\title{
SUICÍDIO EM IDOSOS NO BRASIL: UMA REVISÃO INTEGRATIVA
}

\author{
Moisés Lopes Carvalho' \\ Ana Paula Pinto ${ }^{2}$ \\ Laís Mayara Machado de Amorim ${ }^{3}$ \\ Thaís Regina Carvalho Linhares ${ }^{4}$ \\ Francielzo Ferreira Lima $^{5}$ \\ Moacira Lopes Carvalho 6 \\ Krieger Rhelyni de Sousa Olinda ${ }^{7}$
}

Resumo: As transformações no perfil demográfico e epidemiológico carreados com o envelhecimento da população idosa trazem grande impacto para o Sistema Público de Saúde. Deste modo, contextos e agravos anteriormente inexplorados nesta população começam a ganhar espaço, como é o caso do suicídio neste grupo. Este trabalho teve como objetivo analisar a literatura científica sobre suicídios em idosos no Brasil. O método utilizado para foi a Revisão Integrativa, utilizando bases de dados, como SciELO, portal de periódicos da CAPES e BVS (Biblioteca Virtual em Saúde). Os resultados foram apresentados na forma descritiva, em duas etapas. A primeira consistiu da descrição e análise dos artigos e na segunda, foram agrupados eixos temáticos (Epidemiologia, Fatores associados ao suicídio em idosos e prevenção do suicídio em idosos). Através desta revisão percebe-se que por parte dos familiares e profissionais da saúde deve-se elevar a atenção para as alterações psicossociais do idoso, e subsidiar futuras investigações relacionadas à temática para melhor compreensão, especialmente os fatores envolvidos na prevenção do suicídio na velhice.

Palavras-chave: Suicídio; Tentativa de suicídio; Idoso.

\footnotetext{
1 Universidade do Vale do Paraíba - UNIVAP, Brasil. E-mail: moises.I.carvalho@hotmail.com.

2 Universidade do Vale do Paraíba - UNIVAP, Brasil. E-mail: apaula@outlook.com.br.

3 Universidade do Vale do Paraíba - UNIVAP, Brasil. E-mail: laisinha-16@hotmail.com.

4 Universidade do Vale do Paraíba - UNIVAP, Brasil. E-mail: thaisregina29@hotmail.com.

5 Universidade do Vale do Paraíba - UNIVAP, Brasil. E-mail: francielzolima@hotmail.com.

${ }^{6}$ Centro Universitário UNINOVAFAPI/Radiologia/Enfermagem, Brasil. E-mail: moarabb@hotmail.com.

7 Centro Universitário UNINOVAFAPI/Radiologia/Enfermagem, Brasil. E-mail: paulinhafever@hotmail.com.
} 